Wróblewski Hubert, Zimna Aleksandra. Use of Rifaximin in Irritable Bowel Syndrome Treatment. Journal of Education, Health and Sport. 2021;11(8):247-254. eISSN 2391-8306. DOI http://dx.doi.org/10.12775/JEHS.2021.11.08.025

https://apcz.umk.pl/czasopisma/index.php/JEHS/article/view/JEHS.2021.11.08.025

https://zenodo.org/record/5226929

The journal has had 5 points in Ministry of Science and Higher Education parametric evaluation. § 8. 2) and § 12. 1. 2) 22.02.2019.

This article is published with open access at Licensee Open Journal Systems of Nicolaus Copernicus University in Torun, Poland

Open Access. This article is distributed under the terms of the Creative Commons Attribution Noncommercial License which permits any noncommercial use, distribution, and reproduction in any medium,

provided the original author (s) and source are credited. This is an open access article licensed under the terms of the Creative Commons Attribution Non commercial license Share alike.
(http://creativecommons.org/licenses/by-nc-soper

The authors declare that there is no conflict of interests regarding the publication of this paper.
nathes

Received: 02.08.2021. Revised: 15.08.2021. Accepted: 19.08.2021.

\title{
Use of Rifaximin in Irritable Bowel Syndrome Treatment
}

\author{
Hubert Wróblewski, Aleksandra Zimna \\ Faculty of Medicine, Medical University of Lublin
}

\begin{abstract}
Introduction and purpose of the work: Irritable Bowel Syndrome (IBS) affects up to $10 \%$ of the population. The deterioration in health-related quality of life in IBS patients has been shown to be comparable to, and perhaps even more severe than, other serious chronic organic diseases such as inflammatory bowel disease, diabetes, hypertension, and end-stage renal disease. The aim of the study is to present a new method of IBS treatment.

State of knowledge: There are four main types of IBS: Constipation-predominant IBS (IBS-C), Diarrhea-predominant IBS (IBS-D), Fluctuating IBS (IBS-M), and the unclassified form of IBS (IBS-U). Disturbances in entero-brain interactions play a key role in its multifactorial etiopathogenesis. In patients with IBS, quantitative and qualitative disturbances in the composition of the intestinal microbiota can be found. So far, it has not been possible to clearly establish the cause of the disease, so there is no possibility of causal therapy and effective cure. Both non-pharmacological methods and drugs, including rifaximin $\alpha$, have been used in IBS therapy.

Summary: Rifaximin has a positive effect on the symptoms of IBS. In clinical trials conducted in patients with IBS, the use of rifaximin for 2 weeks was associated with a reduction in the severity of joint symptoms, bloating, abdominal pain and discomfort, and an improvement in stool consistency within 4 and 12 weeks, and did not increase the risk of side effects. In the forms: with predominant diarrhea, mixed and unclassified, in order to reduce the overall symptoms as well as reduce the severity of flatulence and / or diarrhea, a 14-day therapy with rifaximin $\alpha$ is recommended.
\end{abstract}




\begin{abstract}
Abstrakt
Wprowadzenie i cel pracy: Zespół jelita drażliwego (Irritable Bowel Syndrome-IBS) dotyka nawet $10 \%$ społeczeństwa. Wykazano, że pogorszenie jakości życia związanej ze zdrowiem u pacjentów z IBS jest porównywalne, a może nawet bardziej dotkliwe, niż inne poważne przewlekłe choroby organiczne, takie jak nieswoiste zapalenie jelit, cukrzyca, nadciśnienie i schyłkowa niewydolność nerek. Celem pracy jest przedstawienie nowej metody leczenia IBS.

Stan wiedzy: Wyróżnia się cztery główne podtypy IBS: IBS z dominującym zaparciem (IBS-C), IBS z dominującą biegunką (IBS-D), IBS ze zmiennym rytmem wypróżnień (IBS-M) i niesklasyfikowaną postać IBS (IBS-U). W jej wieloczynnikowej etiopatogenezie kluczową rolę odgrywają zaburzenia interakcji jelitowo-mózgowych. $U$ chorych z IBS można stwierdzić ilościowe i jakościowe zaburzenia składu mikrobioty jelitowej. Dotychczas nie udało się jednoznacznie ustalić przyczyny choroby, zatem nie istnieje możliwość terapii przyczynowej oraz skutecznego wyleczenia. W terapii IBS zastosowanie znalazły zarówno metody niefarmakologiczne oraz leki, do których zaliczyć można ryfaksyminę $\alpha$.

Podsumowanie: Ryfaksymina korzystnie wpływa na objawy IBS. W przeprowadzonych badaniach klinicznych u chorych z IBS stosowanie ryfaksyminy przez 2 tygodnie wiązało się ze zmniejszeniem nasilenia łącznych dolegliwości, wzdęcia, bólu brzucha i dyskomfortu oraz poprawą konsystencji stolca w ciągu 4 i 12 tygodni oraz nie zwiększyło ryzyka objawów niepożądanych. W postaciach: z dominującą biegunką, mieszanej i niesklasyfikowanej, w celu zmniejszenia objawów ogółem, jak również zmniejszenia nasilenia wzdęcia i/lub biegunki rekomenduje się 14-dniową terapię ryfaksyminą $\alpha$.
\end{abstract}

Słowa kluczowe: ryfaksymina; zespół jelita nadwrażliwego; leczenie

Wprowadzenie i cel pracy: Zespół jelita drażliwego (Irritable Bowel Syndrome-IBS) dotyka nawet $10 \%$ społeczeństwa. Wykazano, że pogorszenie jakości życia związanej ze zdrowiem u pacjentów z IBS jest porównywalne, a może nawet bardziej dotkliwe, niż inne poważne przewlekłe choroby organiczne, takie jak nieswoiste zapalenie jelit, cukrzyca, nadciśnienie i 
schyłkowa niewydolność nerek. W jej wieloczynnikowej etiopatogenezie kluczową rolę odgrywają zaburzenia interakcji jelitowo-mózgowych.(1) U chorych z IBS można stwierdzić ilościowe i jakościowe zaburzenia składu mikrobioty jelitowej. Dotychczas nie udało się jednoznacznie ustalić przyczyny choroby, zatem nie istnieje możliwość terapii przyczynowej oraz skutecznego wyleczenia. W terapii IBS zastosowanie znalazły zarówno metody niefarmakologiczne oraz leki, do których zaliczyć można ryfaksyminę $\alpha$.

Ryfaksymina $\alpha$, pochodna rimfamycyny, jest antybiotykiem o szerokim spektrum działania swoistym dla przewodu pokarmowego, stosowana w leczeniu biegunki podróżnych, encefalopatii wątrobowej oraz objawowej, niepowikłanej choroby uchyłkowej jelita grubego u dorosłych stosujących dietę bogatoresztkową. Ze względu na jej niskie wchłanianie ogólnoustrojowe i brak istotnych klinicznie interakcji z innymi lekami, ryfaksymina może być obiecującym sposobem leczenia IBS $\mathrm{w}$ postaci $z$ dominującą biegunką, mieszanej i niesklasyfikowanej. Chociaż skuteczność ryfaksyminy została wyraźnie wykazana, mechanizmy odpowiedzialne za korzyści kliniczne ryfaksyminy u pacjentów z IBS-D nie zostały dokładnie ustalone.(2) Celem pracy jest przedstawienie nowej metody leczenia IBS.

\section{Stan wiedzy}

Zespół jelita nadwrażliwego

Jak wcześniej wspomniano, statystycznie nawet co 10 osoba może cierpieć na zespół jelita nadwrażliwego. IBS około dwudziestokrotnie częściej dotyczy kobiet niż mężczyzn, przy czym połowa pacjentów zgłasza pierwsze objawy przed 35. rokiem życia.(1) Wyróżnia się cztery główne podtypy IBS: IBS z dominującym zaparciem (IBS-C), IBS z dominującą biegunką (IBS-D), IBS ze zmiennym rytmem wypróżnień (IBS-M) i niesklasyfikowaną postać IBS (IBS$U) \cdot(3)$

W ostatnim czasie poczyniono znaczne postępy w zakresie kluczowych czynników patogennych, które przyczyniają się do objawów IBS. Pomimo tych postępów, ostatnie badania wśród pacjentów z IBS wskazują, że czekają oni średnio 4 lata na ustalenie rozpoznania IBS, a leczenie pozostaje niezadowalające dla większości pacjentów.(4)

Rozpoznanie zespołu jelita nadwrażliwego można postawić na podstawie wytycznych przedstawionych w Kryteriach Rzymskich IV. Zgodnie z wspomnianymi wcześniej kryteriami IBS musi charakteryzować się występowaniem bólu brzucha nawracający minimum jeden dzień w tygodniu przez ostatnie trzy miesiące, przy wystąpieniu objawów przynajmniej przed sześcioma miesiącami, któremu towarzyszą co najmniej dwie z następujących cech: 1) związany z defekacją, 2) związany ze zmianą częstotliwości wypróżnień, 3) związany ze zmianą konsystencji stolca. (5) Nie należy zapominać, iż u pacjentów z IBS często występują objawy inne niż dotyczące układu pokarmowego, takie jak senność, bóle głowy i pleców w 
okolicy lędźwiowej, nykturia, częste i pilne oddawanie moczu, a u kobiet również zaburzenia miesiączkowania i dyspareunia.(1)

Patofizjologia zespołu jelita nadwrażliwego ma charakter wieloczynnikowy i uważa się, że obejmuje ona takie czynniki, jak dysbioza mikroflory jelitowej, zmieniona przepuszczalność jelit i okrężnicy, aktywacja komórek układu odpornościowego przewodu pokarmowego, nieprawidłowa motoryka przewodu pokarmowego, nadwrażliwość trzewna oraz nieprawidłowe interakcje między jelitami a mózgiem.(3) Dysbioza oznacza zaburzenia składu, proporcji oraz funkcji drobnoustrojów tworzących mikrobiotę. Do dysbiozy może prowadzić wiele czynników, takich jak: dieta, choroby infekcyjne, stosowanie antybiotykoterapii oraz leków, na przykład inhibitory pompy protonowej czy niesteroidowe leki przeciwzapalne, ponadto poziom higieny w danym środowisku czy narażenie na sytuacje stresowe.(2) Przewód pokarmowy człowieka jest zasiedlony przez miliardy drobnoustrojów . (2)W mikroflorze dominują 4 dominujące typy bakterii, z których najliczniejsze to Gramdodatnie Firmicutes (wśród nich ponad 180 gatunków Lactobacillus) oraz Actinobacteria (m.in. Bifidobacteriae), Gram-ujemne Bacteroides (B. Fragilis) oraz Proteobacteria. Zachowanie eubiozy jest ważne dla utrzymania integralności nabłonka jelitowego, tworząc optymalną barierę jelitową chroniącą przed patogenami, a także biorąc udział w pobieraniu składników odżywczych i wytwarzaniu witamin. Dysbioza sprzyja inwazji i wzrostowi gatunków patogennych oraz zaburza homeostazę układu odpornościowego i bariery śluzówkowej.(6)

W przeglądzie systematycznym z 2019 roku wykazano zmienioną mikrobiotę u pacjentów z IBS w porównaniu z osobami zdrowymi. Pacjenci z IBS mieli podwyższony poziom potencjalnie szkodliwych bakterii z rodziny Enterobacteriaceae ( $n=4$ badania) $\mathrm{i}$ gatunków Bacteroides ( $\mathrm{n}=4$ badania), w porównaniu z osobami zdrowymi. Poziomy bakterii z rzędu Clostridiales i rodzaju Faecalibacterium były obniżone u pacjentów z IBS w porównaniu z osobami zdrowymi (po 3 badania)(7). Co ciekawe, pojawiające się dane mogą sugerować, iż określone podgrupy pacjentów z IBS mogą charakteryzować się odrębnym profilem mikroflory jelitowej.(3)

\section{Zastosowanie ryfaksyminy}

Jak wcześniej wspomniano, w terapii IBS zastosowanie znalazły zarówno metody niefarmakologiczne oraz leki, do których zaliczyć można ryfaksyminę $\alpha$. Rifaksymina jest antybiotykiem o niskiej biodostępności po podaniu doustnym. Obecność kwasów żółciowych zwiększa rozpuszczalność ryfaksyminy 70-120-krotnie, co może zwiększać dostępność ryfaksyminy wywierającej działanie przeciwbakteryjne i inne w jelicie cienkim.(3) Wykazuje działanie przeciwdrobnoustrojowe wobec bakterii tlenowych i beztlenowych Gramdodatnich i Gram-ujemnych. Wykazano, że ryfaksymina jest skuteczna w leczeniu biegunki podróżnych, funkcjonalnego wzdęcia i zespołu jelita drażliwego, przerostu bakterii w jelicie cienkim oraz w zapobieganiu nawracającej jawnej encefalopatii wątrobowej. Ponadto pojawiają się dowody na możliwy korzystny wpływ ryfaksyminy w leczeniu niepowikłanej 
choroby uchyłkowej oraz w zapobieganiu nawrotowemu zapaleniu uchyłków. Co istotne, rozwój istotnej lekooporności wśród flory pozajelitowej podczas leczenia ryfaksyminą jest mało prawdopodobny ze względu na minimalne wchłanianie ogólnoustrojowe i ograniczoną oporność krzyżową ryfaksyminy z innymi lekami przeciwdrobnoustrojowymi.(8)

W randomizowanym, podwójnie zaślepionym, kontrolowanym placebo badaniu przeprowadzonym przez Shararę i wsp. u 124 pacjentów z funkcjonalnymi wzdęciami stwierdzono, że rifaksymina w dawce $800 \mathrm{mg} / \mathrm{d}$ była skuteczniejsza niż placebo w zapewnianiu ogólnej ulgi $w$ objawach (odpowiednio $41,3 \%$ vs $22,9 \%, P=0,03$ ). Inne przeprowadzone badanie wykazało ogólną poprawę w porównaniu z grupą placebo wśród osób przyjmujących $1200 \mathrm{mg} / \mathrm{d}$ ryfaksyminy przez 10 dni. Ponadto, po zastosowaniu rifaksyminy nastąpiła znaczna poprawa wzdęcia, podczas gdy ból brzucha, biegunka i zaparcia nie zmieniły się znacząco w porównaniu z placebo.(8)

Skuteczność stosowania ryfaksyminy potwierdziły badania kliniczne III fazy wykonane metodą podwójnie ślepej próby TARGET 1 i TARGET 2. Kryterium wykluczającym z badań była między innymi postać IBS z zaparciami. Pacjentom podawano $550 \mathrm{mg}$ ryfaksyminy 3 razy dziennie przez 2 tygodnie, a następnie obserwowano przez kolejne 10 tygodni. Pierwszorzędowy punkt końcowy stanowił odsetek pacjentów, którzy mieli odpowiednie złagodzenie ogólnych objawów IBS, natomiast drugorzędowy punkt końcowy stanowił odsetek pacjentów, którzy mieli odpowiednie złagodzenie wzdęć związanych z IBS. Istotnie więcej pacjentów w grupie otrzymującej ryfaksyminę niż w grupie placebo miało złagodzenie ogólnych objawów IBS przez co najmniej 2 tygodnie w ciągu pierwszych 4 tygodni 10tygodniowej fazy obserwacji po leczeniu $(40,7 \%$ vs $31,7 \%$ w obu badaniach łącznie) oraz w łagodzeniu wzdęć (40,2 \% vs. 30,3\%). Ponadto, znacznie więcej otrzymujących ryfaksyminę wykazało odpowiedź na leczenie, ocenianą na podstawie dziennych ocen objawów IBS, wzdęć, bólu brzucha i konsystencji stolca.(9) W 2015 r. ryfaksymina została zatwierdzona przez amerykańską Agencję ds. Żywności i Leków (FDA) do leczenia IBS-D.(10)

W celu oceny odpowiedzi u pacjentów z kolejnymi zaostrzeniami wykonano badanie TARGET 3. Zbadano skuteczność ponownego leczenia ryfaksyminą u pacjentów z IBS-D, u których wystąpił objawowy nawrót po początkowym skutecznym leczeniu ryfaksyminą. Spośród 1074 pacjentów, którzy początkowo odpowiedzieli na rifaksyminę w dawce $550 \mathrm{mg}$ 3 razy dziennie przez dwa tygodnie, u 692 nawroty wystąpiły podczas fazy obserwacji, a 636 z nich zostało losowo przydzielonych do drugiego cyklu rifaksyminy (328) lub placebo (308).(10) W przypadku dwóch kolejnych nawrotów objawów (TARGET 3) ryfaksymina $\alpha$ okazała się statystycznie istotnie skuteczniejsza niż placebo w redukcji objawów $(38,1 \%$ vs $31,5 \%, p=0,03)$, zwłaszcza bólu i konsystencji stolca. Osiągnięto również mniejsze ryzyko nawrotu i trwalszą odpowiedź na terapię.(1)

Opublikowano również randomizowane, podwójnie zaślepione, kontrolowane placebo badania dotyczące ryfaksyminy w niezatwierdzonych schematach dawkowania, w połączeniu z antybiotykami ogólnoustrojowymi i/lub u pacjentów z IBS-C (IBS z dominującym zaparciem). Pacjenci z IBS otrzymujący ryfaksyminę $400 \mathrm{mg}$ trzy razy dziennie przez $10 \mathrm{dni}$ doświadczyli znaczącej ogólnej poprawy objawów w porównaniu z pacjentami 
otrzymującymi placebo 10 tygodni po leczeniu. Co więcej, poprawa wzdęcia w ciągu 10 tygodni obserwacji po leczeniu osiągnęła istotność w przypadku ryfaksyminy w porównaniu z placebo $(p=0,01)$. W badaniu pacjentów z IBS-C otrzymujących ryfaksyminę $550 \mathrm{mg}$ trzy razy na dobę plus neomycynę $500 \mathrm{mg}$ dwa razy na dobę przez $14 \mathrm{dni}$, terapia skojarzona spowodowała znacznie większą poprawę nasilenia zaparcia w porównaniu z samą neomycyną 1 tydzień po leczeniu. (3)

\begin{tabular}{|c|c|}
\hline \multicolumn{2}{|c|}{ Działania niepożądane ryfaksyminy } \\
\hline Często & $\begin{array}{l}\text { bóle brzucha, zaparcie, nagła potrzeba } \\
\text { wypróżnienia, bolesne parcie na stolec, } \\
\text { biegunka, wzdęcia, wzmożone napięcie } \\
\text { powłok brzusznych, nudności, wymioty, } \\
\text { gorączka, zawroty głowy, ból głowy, } \\
\text { depresja }\end{array}$ \\
\hline Niezbyt często & 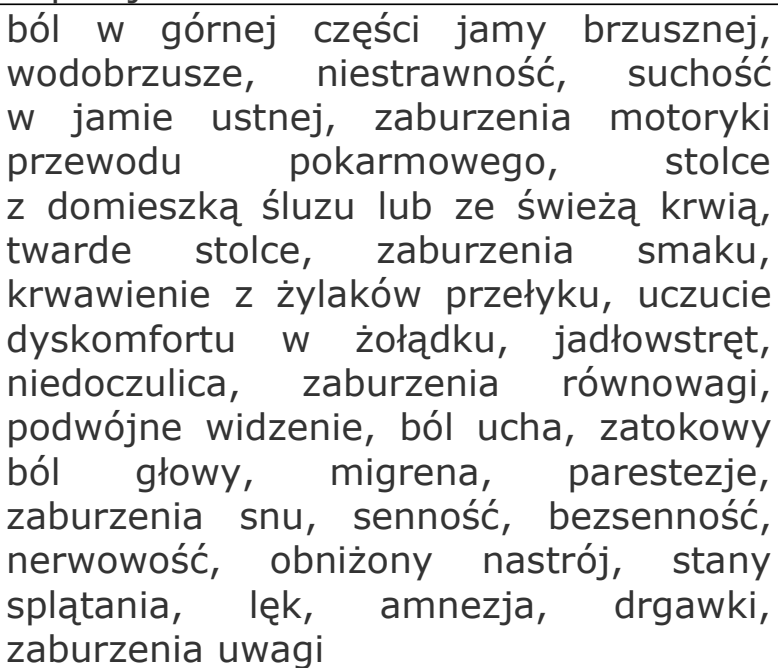 \\
\hline Rzadko & $\begin{array}{l}\text { zapalenie płuc, zapalenie tkanki łącznej, } \\
\text { niedociśnienie, przewlekła obturacyjna } \\
\text { choroba płuc, zaparcie, stłuczenia }\end{array}$ \\
\hline
\end{tabular}

Tabela 1. Działania niepożądane ryfaksyminy (11)

\section{Podsumowanie}

Leczenie IBS jest niezwykle ważne, gdyż objawy powodują znaczne pogorszenie jakości życia. Skuteczność ryfaksyminy można tłumaczyć następująco: ryfaksymina wpływa na bakterie jelitowe i zmniejsza ilość produktów bakteryjnych, wpływa na florę jelitową zmniejszając odpowiedź immunologiczna gospodarza lub antybiotyk wpływa zarówno bakterie, jak i gospodarza (9) Na podstawie opisanych wyżej badań można wywnioskować, iż ryfaksymina korzystnie wpływa na objawy IBS. W badaniach TARGET Częstość objawów niepożądanych była podobna w obu grupach, poważne działania niepożądane wystąpiły u $1,6 \%$ chorych z grupy rifaksyminy i $2,4 \%$ - placebo. W całej grupie badanej nie stwierdzono biegunki związanej z zakażeniem Clostridium difficile, niedokrwiennego zapalenia jelita grubego ani zgonu. $U$ chorych z IBS stosowanie ryfaksyminy przez 2 tygodnie wiązało się ze 
zmniejszeniem nasilenia łącznych dolegliwości, wzdęcia, bólu brzucha i dyskomfortu oraz poprawą konsystencji stolca w ciągu 4 i 12 tygodni oraz nie zwiększyło ryzyka objawów niepożądanych.(10)

Polskie Towarzystwo Gastroenterologii rekomenduje 14-dniową terapię ryfaksyminą $\alpha$ w postaciach: z dominującą biegunką, mieszanej i niesklasyfikowanej, w celu zmniejszenia objawów ogółem, jak również zmniejszenia nasilenia wzdęcia i/lub biegunki. W przypadku pierwszych dwóch nawrotów dolegliwości u pacjentów, którzy odnieśli korzyść z terapii ryfaksyminą $\alpha$, rekomendujemy powtórne leczenie $w$ takim samym schemacie. Minimalny odstęp między cyklami nie został jednoznacznie zdefiniowany; rekomendujemy odstępy między kolejnymi cyklami nie mniejsze niż 4 tygodnie. W najważniejszych badaniach potwierdzających skuteczność ryfaksyminy $\alpha$ w leczeniu objawów stosowano dawkę 1650 mg, W Polsce dostępne są tabletki po $200 \mathrm{mg}$, dlatego w zaleceniach dawkę $1600 \mathrm{mg} \mathrm{(4 \times}$ $400 \mathrm{mg}$ ) należy traktować jako dawkę równoważną i taka powinna być stosowana. Dopuszcza się, choć z zastrzeżeniem odnośnie do spodziewanej mniejszej skuteczności, dawkę 1200 mg. (1)

\section{References}

1. Pietrzak A, Skrzydło-Radomańska B, Mulak A, Lipiński M, Małecka-Panas E, Reguła J, et al. Guidelines on the management of irritable bowel syndrome: In memory of Professor Witold Bartnik. Przegląd Gastroenterol [Internet]. 2018;13(4):259.

2. Skrzydło-Radomańska B, Wronecki J. Czy mikrobiotę jelitową można skutecznie modyfikować? Gastroenterol Klin Postępy i Stand [Internet]. 2018;10(4):123-34.

3. Chey WD, Shah ED, DuPont HL. Mechanism of action and therapeutic benefit of rifaximin in patients with irritable bowel syndrome: a narrative review. Therap Adv Gastroenterol [Internet]. 2020;13.

4. Schoenfeld PS. Advances in IBS 2016: A Review of Current and Emerging Data. Gastroenterol Hepatol (N Y) [Internet]. 2016 Aug;12(8 Suppl 3):1.

5. Adrych K. Zespół jelita drażliwego w świetle najnowszych wytycznych. Varia Medica [Internet]. 2019;3(2):89-95.

6. Raskov H, Burcharth J, Pommergaard H-C, Rosenberg J. Irritable bowel syndrome, the microbiota and the gut-brain axis. Gut Microbes [Internet]. 2016 Sep 2;7(5):365.

7. Pittayanon R, Lau JT, Yuan Y, Leontiadis GI, Tse F, Surette M, et al. Gut Microbiota in Patients With Irritable Bowel Syndrome-A Systematic Review. Gastroenterology [Internet]. 2019 Jul 1;157(1):97-108.

8. Shayto RH, Mrad RA, Sharara Al. Use of rifaximin in gastrointestinal and liver diseases. World J Gastroenterol [Internet]. 2016 Aug 7;22(29):6638.

9. Pimentel M, Lembo A, Chey WD, Zakko S, Ringel Y, Yu J, et al. Rifaximin Therapy for Patients with Irritable Bowel Syndrome without Constipation. http://dx.doi.org/101056/NEJMoa1004409 [Internet]. 2011 Jan 5];364(1):22-32. 
10. Ponziani FR, Pompili M, Gasbarrini A. Rifaximin Re-treatment in Patients with Irritable Bowel Syndrome: Feels Like the First Time? Dig Dis Sci 2017629 [Internet]. 2017 Jun 23;62(9):2220-2.

11. Rifaksymina - Medycyna Praktyczna [Internet]. Available from: https://www.mp.pl/pacjent/leki/subst.html?id=4567 